\title{
Thinking in the Digital Era: A Revised Model for Digital Literacy
}

\author{
Yoram Eshet \\ The Open University of Israel, Raanana, Israel
}

yorames@openu.ac.il

\begin{abstract}
Having digital literacy requires more than just the ability to use software or to operate a digital device; it includes a large variety of complex skills such as cognitive, motoric, sociological and emotional skills that users need to master in order to use digital environments effectively. Unfortunately, the research on digital literacy lacks a well-established theoretical framework. This paper presents an updated version of the skills-based theoretical framework, published by EshetAlkalai in 2004 - adding to it a sixth skill (real-time thinking skill), and discussing the model in light of the recent literature on digital literacy. The updated model of digital literacy consists of the following skills: photo-visual skills (understanding messages from graphical displays), reproduction skills (utilizing digital reproduction to create new, meaningful materials from preexisting ones), branching skills (constructing knowledge from non-linear, hypertextual navigation), information skills (critically evaluating the quality and validity of information), socio-emotional skills (understanding the "rules" that prevail in the cyberspace and applying this understanding in virtual communication), and real-time thinking (the ability to process large volumes of stimuli at the same time, as in video games or in online teaching). The present paper presents results from performance-based studies of the author, that investigated the application of the above digital literacy skills conceptual model among different groups of users. Results clearly indicate that the younger participants performed better than the older ones, with photo-visual and branching literacy tasks, whereas the older participants were found to be more "digitally-literate" in reproduction and information literacy tasks. The paper presents findings from recent studies that examined change over time in digital literacy skills. It sheds light on the cognitive skills that users utilize in performing with digital environments, and provides educators and software developers with helpful guidelines for designing better user-centered digital environments.
\end{abstract}

Keywords: digital literacy, digital skills, usability, critical thinking, branching skills, photo-visual skills, real-time skills, socio-emotional skills, reproduction skills

\section{Introduction}

Material published as part of this publication, either on-line or in print, is copyrighted by the Informing Science Institute. Permission to make digital or paper copy of part or all of these works for personal or classroom use is granted without fee provided that the copies are not made or distributed for profit or commercial advantage AND that copies 1 ) bear this notice in full and 2) give the full citation on the first page. It is permissible to abstract these works so long as credit is given. To copy in all other cases or to republish or to post on a server or to redistribute to lists requires specific permission and payment of a fee. Contact Publisher@InformingScience.org to request redistribution permission.
The proliferation of technologies during the digital era confronts individuals with situations that require the utilization of an ever-growing assortment of technical, cognitive, and sociological skills that are necessary in order to perform effectively in digital environments. These skills are termed in literature 'digital literacy' (Buckingham, 2003; Gilster, 1997; Hargittai, 2008; Lankshear \& Knobel, 2008). As pointed out by Bawden 
(2001), digital literacy is more than just the technical ability to operate digital devices properly; it comprises a variety of skills that are utilized in executing tasks in digital environments, such as constructing knowledge during surfing the web, deciphering user interfaces, playing digital games, searching in databases, creating and sharing content on the web, chatting in chat rooms and communicating in social networks (Hargittai, 2008; Jones-Kavalier \& Flannigan, 2006).

In the modern era, digital literacy has become a "survival skill" - a key that helps users to work intuitively in executing complex digital tasks. In recent years, extensive efforts are made to describe and conceptualize the cognitive skills that users employ in digital environments (e.g., Hargittai, 2008; Marsh, 2005). Unfortunately, these efforts are usually local, focusing on a selected and limited variety of skills, mainly information-seeking skills (e.g., Bawden, 2008; Lankshear \& Knobel, 2008; Zins, 2000), and, therefore, they do not cover the full scope of the term digital literacy. Eshet-Alkalai (2004) has established a holistic conceptual model for digital literacy, arguing that it covers most of the cognitive skills that users and scholars employ while working in digital environments and, therefore, providing researchers and designers of digital environments with a powerful framework and design guidelines. This framework was derived from the analysis of large volumes of empirical and qualitative data regarding the behavior of users in digital environments and was studied empirically by Eshet and Amichai-Hamburger (2004), who tested the performance of different groups of computer users with tasks that require the utilization of different digital skills. The publication of Eshet-Alkalai's model of digital literacy has led to an extensive debate within the community of instructional technology designers, researchers and educators, as to its validity and completeness. This debate (Aviram \& Eshet, 2006) confirmed the validity and value of the model, but indicated that it lacked a sixth thinking skill: the Real-time thinking skill, which relates to the ability of users to perform effectively in advanced digital environments, mainly high-tech machines, multimedia games and multimedia training environments, that require the user to process simultaneously large volumes of stimuli which appear in real-time and at high-speed.

The present paper presents an updated version of the holistic model of Eshet-Alkalai (2004). The real-time thinking skill is added to the model and its value in refining our understanding of how people interact with digital environments and communicate with others in the cyberspace, is discussed in light of the recent, knowledge on digital literacy. The digital thinking skills that are discussed in the paper are the photo-visual, reproduction, branching, information, socio-emotional and real-time thinking skills. It is argued that these six digital thinking skills exist in every learner, but their "volume" or "magnitude" depends on the situation and differ from person to person.

In the following paragraphs, the revised holistic model for of digital literacy and its six thinking skills, are discussed in detail.

\section{Photo-visual Digital Skills}

The evolution of digital environments, from text-based, syntactic to graphic-based semantic environments (Nielsen, 1993; Shneiderman, 1998; Soffer \& Eshet-Alkalai, 2009), requires users of modern digital environments to employ cognitive skills of "Using Vision to Think" (Mullet \& Sano, 1995) in order to create an effective photo-visual communication with the environment. This unique form of digital thinking skill - the photo-visual skill - helps users to intuitively and freely 'read' and understand instructions and messages that are presented in a visual-graphical form. Good examples of digital environments that require the utilization of photo-visual digital skills can be found in the design of graphic user interfaces (Opperman, 2002; Shneiderman, 1998) and in children's modern computer games (Carlsson, 2006) - in both, all usage instructions are provided through a graphical representation of symbols and icons. Today, with the infiltration of games from the children to the adult world (Henderson, Eshet-Alkalai \& Klemes, 2008) and with the proliferation of "serious games" in professional training (Michael \& Chen, 2005), the photo- 
visual skills are becoming essential for effective workers and scholars. Successful photo-visual users usually have a good visual memory and strong intuitive-associative thinking that are useful in understanding visual messages (Nielsen, 1993). Eshet-Alkalai and Amichai-Hamburger (2004) discovered that young users (school children) of graphic digital environments performed significantly better than adults (30-40 years old) in usability-based tasks that required the utilization of photo visual skills. The tasks required deciphering a user-interface of an unknown program. Surprisingly, Eshet-Alkalai and Chajut (2009; 2010), who studied the performance of the same group of users after five years, found that this gap almost closed and the photo-visual performance of the adults and the young users became almost the same.

\section{Reproduction Digital Skills}

The modern digital technologies provide scholars with new possibilities for creating art and academic work by reproducing and editing existing texts, visuals and audio pieces (Benjamin, 1994; Gilster, 1997; Soffer \& Eshet-Alkalai, 2010). With the growing accessibility of technologies for free and open information resources, such as Wikipedia and blogs (Bruns, 2008), scholars face a wide range of ethical and philosophical questions regarding the limits and criteria for legitimategenuine use of digital reproduction (Aviram \& Eshet, 2006), as expressed with the growing amount of plagiarism, detected among digital users (Xin, Francia, Ming, McKinnon \& Seker, 2004).

Besides these ethical challenges, the digital reproduction technologies require modern scholars to master a special assortment of cognitive skills, termed here 'Reproduction digital skills. Reproduction digital skills are defined as the ability to create new meanings or new interpretations by combining preexisting, independent shreds of information in any form of media (text, graphic, or sound) (Gilster, 1997). These skills are essential in two major fields: In writing, where preexisting sentences can be reorganized and rearranged to create new meanings, and in art, where preexisting audio or visual pieces can be edited and manipulated in order to create new art works (as in the case of Pop Art, where art-works are made of a collage of preexisting graphic elements). Labbo, Reinking and McKenna (1998) and Korat (2010) described problems that learners face in the digital reproduction of text in a variety of work situations. According to them, scholars who have a high level of digital reproduction skills also have a good, synthetical and multidimensional thinking that helps them in discovering new combinations for arranging information in new, meaningful ways. Opposite to their findings for the photo-visual skills, Eshet and AmichaiHamburger (2004) found that adult (30-40 years old) scholars owned a significantly higher level of digital reproduction skills compared to younger school children, when performed with tasks that require creativity in utilizing digital reproduction skills. The tasks required assigning a new meaning to text paragraphs by re-arranging the words and sentences in them. In their follow-up study on the same research population, Eshet-Alkalai and Chajut (2009; 2010), found that unlike their findings for the photo-visual skills, in the reproduction skills, the difference between the younger and the older participants increased significantly after five years.

\section{Branching Digital Skills}

The non-linear, branching nature of the modern hypermedia technology introduced computer users to new dimensions of thinking that are necessary in order to make an educated use of this elaborate technology. In the past, the limited, non-hypermedia-based computer environments enhanced a more linear way of learning, which was dictated by the non-flexible operating systems and by the fact that users were used to books and expected to work with digital environments in much the same way they read through books. The modern multimedia environments, digital books, the Internet, digital databases, provide users with a high degree of freedom in navigating through knowledge domains, but at the same time, confront them with problems that involve the 
need to utilize non-linear and branching information-seeking strategies and to construct knowledge from independent shreds of information that were accessed in a non-orderly and non-linear way (Balcytiene, 20003; Jansen \& Pooch, 2001; Rouet, 2000; Zins, 2000). Spiro, Fwltovitch, Jacobson \& Caulson, (1991) presented the Cognitive Flexibility Theory, that described the importance of branching, multidimensional thinking skills in constructing meaningful understanding of complex phenomena. According to them, the hypermedia technology led to the evolution of new types of digital thinking skills, termed here 'branching digital skills,' or 'Hypermedia skills.' Branching digital skills require scholars to have a good spatial-multidimensional sense of orientation - the ability to stay oriented and avoid getting lost in the hyperspace while navigating through complex knowledge domains, despite the intricate navigation paths they may take (Lazar, Bessier, Ceaparu, Robinson \& Schneiderman, 2003). In recent years, readers of digital text face difficulties in knowledge construction, which results from the growing tendency to embed a large number of hyperlinks in the text, as in most items of Wikipedia and in many digital textbooks (Meyers, 2011).

As shown by Eshet-Alkalai and Amichai-Hamburger (2004), successful "branching-literate" users have a good metaphoric thinking and the ability to create mental models, concept maps, and other forms of abstract representation of the web's structure, which help them overcome disorientation problems in hypermedia environments.

Similar to their findings for the digital photo-visual skills, Eshet and Amichai-Hamburger (2004) found that the younger, school-student participants, owned a significantly higher level of branching skills, compared to the older (30-40 years old) participants, in usability-based tasks that required the utilization of digital branching skills, such as using the Internet in order to plan a trip in a foreign country. The tasks tested the users' ability to create knowledge in a non-linear way. Eshet-Alkalai and Chajut (2009; 2010), found that after five years, the gap between these two groups diminished significantly and the adults' performance almost equaled the performance of the young participants.

\section{Information Digital Skills}

The exponential growth in the amount of available information, side by side with the proliferation of social networks, blogs, podcasts, wikkis and file-sharing technologies, led to the relatively new phenomenon of information decentralization, in which the contribution of new information by the users becomes increasingly more essential (Bruns, 2008). In this situation (termed "Produscage", or "The Age of the Producers", by Burns), where information consumers are "bombarded" by large volumes of information, whose authority and authenticity are not always clear, the ability of consumers to assess information effectively, by sorting out subjective, biased or even false information, has become a key issue in training people to become smart information consumers (Buckingham, 2003; Eshet-Alkalai, 2004; Kerka, 1999). Information assessment is made in almost every work we do in digital environments, such as in data queries or in navigational decisions we make in the web, but it is the awareness of the users to decisions they make, that determines the actual quality of the conclusions, positions, opinions, or models that they construct from the information (Paul \& Elder, 2005; Saranto \& Hovenga, 2004).

It is true that information thinking skills are not unique to the digital era; they were always crucial traits of successful scholars, even before the information revolution ( Wilton \& Meyers, 1986). However, in the digital era, with the unlimited exposure of humans to digital information, these skills have become real "survival skills", that enable learners to make educated uses of information. Unfortunately, most studies of information digital skills focus on the information search strategies and habits of users (e.g. Bus \& Neuman, 2009; Morahan-Martin \& Anderson, 2000; Zins, 2000), and only a few stress the cognitive and pedagogical aspects that are relevant to these skills (e.g. Burnett \& McKinley, 1998; Minkel, 2000; O’Sullivan, 2000). The ability of informa- 
tion consumers to make educated, smart information assessment requires a special kind of thinking skills, termed here 'Information digital skills'. Information skills act as a filter: They help identify false, irrelevant, or biased information, and avoid its penetration into the learner's cognition. Skilled information consumers are critical thinkers - people who always question information and never take it for granted (Paul \& Elder, 2005).

Eshet and Amichai-Hamburger (2004) found that 30-40 years old adults performed significantly better than school children in exercising digital information skills, when asked to employ critical thinking by analyzing manipulative-biased news items in Internet news sites. Eshet-Alkalai and Chajut (2009; 2010), found that five years later, the gap between these two groups increased significantly: The information skills of the younger participants decreased significantly, whereas those of the older participants didn't change.

\section{Socio-emotional Digital Skills}

The expansion of platforms for digital communication and knowledge-sharing in recent years, has opened new dimensions and opportunities for learning, collaborating and forming relationships trough knowledge-sharing groups, discussion groups, knowledge communities, chat rooms, social networks (Boyd, 2007) and many other forms of collaborative learning (e.g. Twitter, Facebook and other social networking technologies) (Ardichvilli, Page \& Wentling, 2003; Bruns, 2008; Roblyer, McDaniel, Webb, Herman \& Witty, 2010). But these new opportunities face users with challenges that require them to employ sociological and emotional skills in order to "understand the rules of the game" and "survive" the hurdles that await them in the mass communication that takes place in the cyberspace (Boyd, 2007; Bruns, 2008; Roblyer et al., 2010; Utz, 2000). Such challenges include not only the ability to share formal knowledge (Wang \& Noe, 2010), but also to share emotions in digital communication (Amichai-Hamburger, 2002; Amichai-Hamburger \& Hayat, 2011), to identify deception in chat rooms (Caspi \& Gorsky, 2006) and to avoid Internet traps as a hoax and malicious Internet viruses. These require users to own a relatively new assortment of digital skills, termed 'Socio-emotional skills' in the present paper, because they involve primarily emotional and sociological aspects of working in the cyberspace. Among all the types of digital thinking skills described here, the socio-emotional skills are probably the newest and most complex; they emerged only in the last decades, with the exponential spread of Internet communication (Bruns, 2008), and they require users who are very critical and analytical, very mature, and have a good command of information, branching, and photo-visual digital thinking skills. In recent years, efforts are made to portray the sociological and psychological profile of the skilled cyberspace user (e.g. Amichai-Hamburger, 2002; Amichai-Hamburger \& Hayat, 2011; Caspi \& Gorsky, 2006; Hamburger \& Ben-Artzi 2000; Mundrof \& Laird, 2002; Utz, 2000). From the results of these studies, we can describe the socio-emotional-skilled users of digital environments as willing to share their own data and knowledge with others (McLure, Wasko \& Faraj, 2000; Ardichvilli et al., 2003(Wang \& Noe, 2010), capable of evaluating data, possessing an abstract thinking, and able to design knowledge through virtual collaboration. No clear empirical trends are evident among different age-groups, in analyzing the performance of users with tasks that require the utilization of socio-emotional digital skills (Eshet \& Amichai-Hamburger, 2004), indicating the emerging and yet unclear nature of this new and complex skill, and suggesting that its use is still not well established among users of the modern communication digital platforms.

\section{Real-time Digital Skills}

Modern digital working environments, such as multimedia environments, digital games, microworld simulations and different digital tools, are characterized by the fact that they "bombard" the user's cognition in real-time with large volumes of fast-moving stimuli of different kinds, such as sound, text and images (Bavelier et al., 2011; Gredler, 2004). In all these situations the key to 
the users' successful performance is their ability to effectively process these simultaneous stimuli. When operating such environments, users need to split their attention, reacting to various kinds of stimuli that appear simultaneously in different places on the monitor (Green \& Bavelier, 2003); they have to be able to execute different tasks simultaneously (multi-tasking) and stay on-task as they switch their attention from one task to the other (multi tasking, or "Task Switching" according to Monsell, 2003); they need to be able to rapidly change their angle of view and perspective of the environment; they have to respond to feedback that appears in real-time. And above all they have to quickly and effectively synchronize the chaotic multimedia stimuli into one coherent body of knowledge (Eshet-Alkalai \& Chajut, 2007).

Today, situations that require real-time and high speed processing of simultaneous large fluxes of information have become common in our lives, mainly in operating multimedia programs and advanced machines. This requires that users of today's digital environments master a special kind of thinking skill, here termed "real time thinking". Of course, real time thinking is not new; it has been utilized ever since humans began to think and to synchronize information simultaneously in order to create knowledge. But in the digital era, with the central role of fast computers, multimedia environments, and devices that can process and present information in real-time and at high speed, real-time thinking has become a critical skill.

Studies from the Operations Research field showed that human's performance with real-time environments, such as action video games (Green \& Bavelier, 2003), aircrafts (e.g. Roessingh, 2005) and car-driving (Casimir \& Gilchrist, 2002) improved dramatically by using training simulations that improve real-time thinking skills. Very little research has been done on the "soft" pedagogic aspects of real-time learning, such as digital games (Fromme, 2003; Pemberton et al., 2004). However, Eshet-Alkalai and Chajut (2007) reported on a foreign-language acquisition process by the effective synchronization of simultaneous audio and visual stimuli in digital storey-telling environments.

\section{Discussion}

This paper proposes a revision of the five-skills pioneering conceptual model of Eshet-Alkalai (2004) and examines its validity with respect to the present-days research literature on the performance of users with digital environments. In the paper, a sixth digital skill - the real-time thinking skill, which was missing in the original model of Eshet-Alkalai, is added, making it a holistic-updated model for digital literacy, which covers the full scope of the critical skills for effective performance in the digital era. According to the revised model, digital literacy consists of six thinking skills (i.e. photo-visual, branching, reproduction, information, socio-emotional and real-time skills), which are employed during human interactions with modern digital environments.

The importance of the revised model for digital literacy lies in the fact that most research in this field is of a practice-oriented nature, stemming from the experience of designers and educators, and in the fact despite the numerous studies on digital literacy, it still lacks a sound theoretical foundation. In the works of Eshet-Alkalai (2004), Eshet-Alkalai \& Amichai-Hamburger (2004), and Eshet-Alkalai and Chajut (2009, 2010), the very first steps were taken in the necessary direction: the integration of different digital skills into a coherent framework, and their testing in empirical studies. The present paper is one step ahead in refining this theoretical model and developing a theoretical framework for the discussion of digital literacy. Application of this framework may improve communication among learners and developers, by providing a diagnostic and evaluative tool for use in creating precise, user-directed products. The empirical studies which tested the utility of this digital literacy model (Eshet-Alkalai\& Amichai-Hamburger, 2004), clearly indicate that younger users perform better than older users in skills of a usability nature (e.g. photo-visual skills), whereas, the older participants perform better in skills that require crea- 
tivity (e.g. reproduction skill) and critical thinking (e.g. information skills). A study that examined change over time in digital literacy skills (Eshet-Alkalai \& Chajut, 2009, 2010), showed that the gap between the younger and the older participants closed for the "usability-directed skills", whereas this gap increased for the creative and critical thinking skills.

Future studies should focus on refining the proposed model for digital literacy and on the examination of changes through time in the digital skills among special groups such as gender and people with learning disabilities.

\section{References}

Amichai-Hamburger, Y. (2002). Internet and personality. Computers in Human Behavior, 18, 1-10.

Amichai-Hamburger, Y., \& Hayat, Z. (2011). The impact of the Internet on the social lives of users: A representative sample from 13 countries. Computers in Human Behavior, 27(1), 585-589.

Ardichvilli, A., Page, V., Wentling, T. (2003). Motivation and barriers to participation in virtual knowledge sharing communities of practice. Journal of Knowledge Management, 7(1), 64-77.

Aviram, R., \& Eshet, Y. (2006). Towards a theory of digital Literacy: Three scenarios for the next steps. European Journal of Open Distance Learning. Retrieved, January 31 ${ }^{\text {st }}, 2011$ from http://www.eurodl.org/materials/contrib/2006/Aharon_Aviram.htm

Balcytiene, A. (2003). Exploring individual processes of knowledge construction with hypertext. Instructional Science, 27(4), 303-328.

Bavelier, D., Shawn Green, C., Hyun Han, D., Renshaw, P. F., Merzenich, M. M., \& Gentile, D. A. (2011). Brains on video games. Nature Reviews Neuroscience, 12, 763-768.

Bawden, D. (2001). Information and digital literacies: A review of concepts. Journal of Documentation, 57 (2), 218-259.

Bawden, D. (2008). Origins and concepts of digital literacy. In Lankshear \& Knobel (Eds.), Digital literacies: Concepts, policies and practices (pp. 17-33). New York: Peter Lang Publishing.

Benjamin, W. (1994). The work of art in the age of technical reproduction [Hebrew translation from German]. Tel Aviv: Teamin Publishers.

Boyd, D. (2007). Social network sites: Definition, history, and scholarship. Journal of Computer Mediated Communication, 13(1), 210-230.

Bruns, A. (2008). Blogs, Wikipedia, Second Life, and beyond: from production to produsage. New York, New York: Peter Lang, Publishing.

Buckingham, D. (2003). Media education and the end of the critical consumer. Harvard Educational Review, 73(3), 309-328.

Buckingham, D. (2008). Defining digital literacy: What do young people need to know about digital media? In Lankshear \& Knobel (Eds.), Digital literacies: Concepts, policies and practices (pp. 73-85). New York: Peter Lang Publishing.

Burnett, K., \& McKinley, E. G. (1998). Modeling information seeking. Interacting With Computers, 10, 285-302.

Bus, A. G., \& Neuman, S. B. (Eds). (2009). Multimedia literacy development. New York: Routledge.

Carlsson, U. (Ed.). (2006). Regulation, awareness, empowerment: Young people and harmful media content in the digital age. In The International Clearinghouse on Children, Youth and Media. Nordcom/Goteborg: University Press.

Caspi, A., \& Gorsky, P. (2006). Online deception: Prevalence, motivation and emotion. Cyberpsychology \& Behavior, 9(1), 54-59. 
Casimir, J. L., \& Gilchrist, I. (2002). Stimulus-driven and goal-driven control over visual selection. Journal of Experimental Psychology: Human Perception and Performance, 28, 902-912.

Eshet-Alkalai, Y (2004). Digital literacy: A conceptual framework for survival skills in the digital era. Journal of Educational Multimedia and Hypermedia, 13(1), 93-106.

Eshet-Alkalai, Y., \& Amichai-Hamburger, Y. (2004). Experiments in digital literacy. CyberPsychology and Behavior, 7(4), 425-434.

Eshet-Alkalai, Y., \& Chajut, E. (2007). Living books: The incidental bonus of playing with multimedia. Journal of Educational Multimedia \& Hypermedia, 16(4), 377-388.

Eshet-Alkalai, Y., \& Chajut, E. (2009). Changes over time in digital literacy. Cyberpsychology \& Behavior, 12. DOI: $10.1089=$ cpb.2008.0264

Eshet-Alkalai, Y., \& Chajut, E. (2010). You can teach old dogs new tricks: The factors that affect changes over time in digital literacy. Journal of Information Technology Education, 9, 173-181. Retrieved from http://www.jite.org/documents/Vol9/JITEv9p173-181Eshet802.pdf

Fromme, J. (2003). Computer games as a part of children's culture. The International Journal of Computer Games Research, 3(1). Retrieved January, 31ast, 2012, http://gamestudies.org/0301/fromme/

Gilster, P. (1997). Digital literacy. N.Y: Wiley Computer Publishing.

Gredler, M. E. (2004). Games and simulations and their relationships to learning. In D.H. Jonassen (Ed.), Handbook of research on educational communications and technology (2nd ed.) (pp. 571-581). Mahwah, NJ: Lawrence Erlbaum.

Green, C. S., \& Bavelier, D. (2003). Action video game modifies visual selective attention. Nature, 423, 534-536.

Hamburger, Y. A., \& Ben-Artzi, E. (2000). The relationships between extraversion and neuroticism and the different uses of the Internet. Computers in Human Behavior, 16, 441-449.

Hargittai, E. (2002). Beyond logs and surveys: In-depth measures of people's Web use skills. Journal of the American Society for Information Science and Technology, 53(14), 1239-1244.

Hargittai, E. (2008). Survey measures of web-oriented digital literacy. Social Science Computer Review, 23, 371-379.

Henderson, L., Eshet-Alkalai, Y., \& Klemes, J. (2008). Digital gaming: A comparative international study of youth culture in a peaceful and war zone country. Eludamos. Journal for Computer Games Culture, 2(1), 73-103.

Jansen, B. J. \& Pooch, U. (2001). A review of web searching studies and a framework for future research. Journal of the American Society for Information Science and Technology, 52, 235-246.

Jones-Kavalier, B. R., \& Flannigan, S. L. (2006). Connecting the digital dots: Literacy of the $21^{\text {st }}$ century. Educause Quarterly, 2, 8-10.

Kerka, S. (1999). Consumer education for the information age. Practice Application Brief, 4, 12-15.

Korat, O. (2010). Reading electronic books as a support for vocabulary, story comprehension and word reading in kindergarten and first grade. Computers \& Education, 55, 24-31.

Lankshear, C., \& Knobel, M. (Eds.). (2008). Digital literacies: Concepts, policies and practices. New York: Peer Lang Publishing.

Labbo, L. D., Reinking, D., \& McKenna, M. C. (1998). Technology and literacy education in the next century: Exploring the connection between work and schooling. Peabody Journal of Education, 73, 273289.

Lazar, J., Bessiere, K., Ceaparu, I., Robinson, J., \& Shneiderman, B. (2003). Help! I’m lost: User frustration in web navigation. IT \& Society, 1, 18-26. 
Marsh, J. (2005). Popular culture, new media and digital literacy in early childhood. NY: Routledge Taylor \& Francis Group.

McLure, M., \& Faraj, S. (2000). It is what one does: Why people participate and help others in electronic communities of practice. Journal of Strategic Information Systems, 9, 155-173.

Meyers, P. (2011). Linking in ebooks: How much is too much? Oreilly Radar, October, 2011. Retrieved from http://radar.oreilly.com/2011/10/ebook-linking-considerations.html

Michael, D. R., \& Chen, S. L. (2005). Serious games: Games that educate, train, and inform. NY: Muska \& Lipman/Premier-Trade.

Minkel, W. (2000). No, it’s not all true! Library Journal, 12, 33-34.

Monsell, S. (2003). Task switching. Trends in Cognitive Sciences, 7(3), 134-140.

Morahan-Martin, J., \& Anderson, C. D. (2000). Information and misinformation online: Recommendations for facilitating accurate mental health information retrieval and evaluation. CyberPsychology \& Behavior, 3, 731-746.

Mullet, K., \& Sano, D. (1995). Designing visual interfaces. Englewood Cliff, NJ: Prentice Hall.

Mundrof, N., \& Laird, K. R. (2002). Social and psychological effects of information technologies and other interactive media. In J. Bryant \& D. Zillman (Eds.), Media effects: Advances in theory and research (2nd ed.) (pp. 231-255). Mahwah, NJ: Erlbaum.

O’Sullivan, M. (2000). Teaching internet information literacy: A collaborative approach (Part III). Multimedia Schools, 7, 34-37.

Nielsen, J. (1993). Usability engineering. San Diego: Morgan Kaufman.

Opperman, R. (2002). User interface design. In H. H. Adelsberger, B. Collis, \& J. M. Pawlowski, Handbook on information technologies for education and training (pp. 233-248). Berlin: Springer-Verlag.

Paul, R., \& Elder, L. (2005). A guide for educators to critical thinking competency standards: Standards, principles, performance. Dillon Beach, CA: Foundation for Critical Thinking.

Pemberton, L., Fallahkhair, S., \& Masthoff, J. (2004). Towards a theoretical framework for informal language learning via interactive television. In D. Kinshuk, G. Sampson, \& P. Isaias, (Eds.), Cognition and exploratory learning in the digital age (CELDA 2004), pp. 27-34. Lisbon, Portugal: IADIS Press.

Roblyer, M. D., McDaniel, M., Webb, M., Herman, J., \& Witty, J. V. (2010). Findings on Facebook in higher education: A comparison of college faculty and student uses and perceptions of social networking sites. The Internet and Higher Education, 13(3), 134-140.

Roessingh, J. M. (2005). Transfer of flying manual skills from PC-based simulation to actual flightcomparison of in-flight measured data and instructor ratings. International Journal of Aviation Psychology, 1, 67-90.

Rouet, J. F. (2000). Hypermedia and learning: Cognitive perspectives. Journal of Computer-Assisted Learning, 16, 97-101.

Saranto, K., \& Hovenga, E. J. (2004). Information literacy-what it is about? Literature review of the concept and the context. International Journal of Medical Information, 73(6), 503-513.

Shneiderman, B. (1998). Designing the user interface. Reading, MA: Addison-Wesley.

Soffer, O., \& Eshet-Alkalai, Y. (2009). Back to the future: An historical perspective on the pendulum-like changes in literacy. Minds and Machines, Journal for Artificial Intelligence, Philosophy and Cognitive Science, 19(1), 47-59.

Spiro, R. J., Feltovitch, P. L., Jacobson, M. J., \& Coulson, R. L. (1991). Cognitive flexibility, constructivism and hypertext: Random access instruction for advanced knowledge acquisition in ill-structured domains. Educational Technology, 31, 24-33.

Tapscott, D. (1998). Growing up digital: The rise of the net generation. NY: McGraw-Hill. 
Utz, S. (2000) Social information processing in MUDs: The development of friendships in virtual worlds. Journal of Online Behaviour, 1(1). Retrieved January, 31, 2012 from http://www.behavior.net/JOB/v1n1/utz.html

Wang, S. \& Noe, R. A. (2010). Knowledge sharing: A review and directions for future research. Human Resource Management Review, 20(2), 115-131.

Wilton, P. C., \& Myers, J. G. (1986). Task, expectancy and information assessment effects in information utilization process. Journal of Consumer Research, 12, 469-486.

Xin, C., Francia, B., Ming L., McKinnon, B., \& Seker, A. (2004). Shared information and program plagiarism detection. Information Theory, IEEE Transactions, 50(7), 1545-1551. Zins, C. (2000). Success, a structured search strategy rationale, principles and implications. Journal of the American Society for Information Science, 51, 1232-1247.

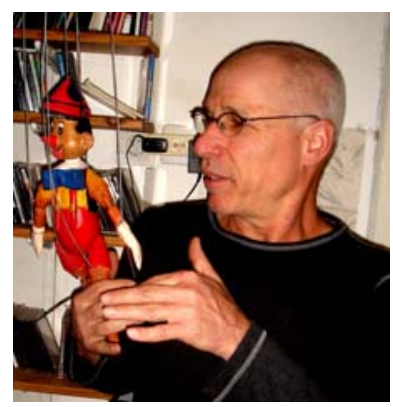

\section{Biography}

Yoram Eshet is a Full Professor at the Open University of Israel, Department of Education \& psychology. He is the Coordinator of the M.A. program in educational technology and wrote several M.A.-level textbooks on technology \& learning and on design-principles of computer-based learning. He is the Founder and Head of the Chais Research Center for the Integration of Technology in Education (www.chais.openu.ac.il). Yoram has a diverse academic and professional background: He holds a B.A in Archeology, M.Sc. in Geology and $\mathrm{PhD}$ in Earth \& Environmental Sciences. For a decade, he was the Head of the Instructional Design Program in the Tel Hai Academic College and a senior researcher in the Geological Survey of Israel. 